Check for updates

Cite this: RSC Adv., 2017, 7, 46183

\title{
A study on the mechanical, thermal properties and crystallization behavior of poly(lactic acid)/ thermoplastic poly(propylene carbonate) polyurethane blends
}

\author{
Jia Yang, ${ }^{\text {abc }}$ Hongwei Pan, ${ }^{\text {bc }}$ Xin Li, ${ }^{\text {abc }}$ Shulin Sun, ${ }^{a}$ Huiliang Zhang (D) *b \\ and Lisong Dong
}

Poly(lactic acid) (PLA) was toughened by the thermoplastic poly(propylene carbonate) polyurethane (PPCU), and the mechanical properties, crystallization behaviour and enzymatic degradation of the PLA/PPCU blends were investigated. The mechanical testing results showed that the impact strength and elongation at break of PLA/PPCU blends were remarkably higher than those of pure PLA. The impact strength was enhanced from $4.8 \mathrm{~kJ} \mathrm{~m}^{-2}$ for pure PLA to $102.8 \mathrm{~kJ} \mathrm{~m}^{-2}$ for the 50/50 PLA/PPCU blend. The impact testing showed obvious ductile fracture after PLA was blended with PPCU. It was found that the PLA matrix showed large plastic deformation (shear yielding) in the blend subjected to impact tests, which is an important energy-dissipation process and led to a toughened polymer blend. PPCU could act as an impact modifier for PLA. The maximum improvement in the cold crystallization temperature $\left(T_{c c}\right)$ value was observed for PLA/PPCU blends where $T_{c c}$ was increased from $113^{\circ} \mathrm{C}$ to $128^{\circ} \mathrm{C}$. PPCU enhanced the crystallization degree of PLA, but the positive function of crystallization was weakened when the content of PPCU was increased from 10 to $50 \mathrm{wt} \%$. Isothermal crystallization kinetics showed that PPCU improved the crystallinity of the PLA and reduced the crystallization rate of blends. And the incorporation of PPCU did not alter the crystal structure of the PLA matrix. The PLA/PPCU blends were high strength and high toughness, entirely biodegradable materials, which is important for manufacture and application.

Received 5th July 2017

Accepted 21st September 2017

DOI: $10.1039 / \mathrm{c} 7 \mathrm{ra07424g}$

rsc.li/rsc-advances nanofibers, ${ }^{15}$ poly[(butylene adipate)-co-terephthalate $](\mathrm{PBAT}),{ }^{16-18}$ thermoplastic polyurethane(TPU) ${ }^{19-22}$ and poly(propylene carbonate) (PPC) ${ }^{23,24}$ were used for flexibilizer of PLA. Pongtanayut et $a l^{25}$ have reported that the properties of PLA/natural rubber (NR) and PLA/epoxidized natural rubber (ENR) were compared with the properties of PLA. Kanzawa et $a l .{ }^{26}$ have improved the mechanical properties of PLA/PBAT blends, examining the morphological changes of PLA/PBAT/PC, and elucidating the mechanism for improvement of the mechanical properties of the blends. Zou et al. ${ }^{24}$ have reported that PLA/PPC blends were prepared via vane extruder with a short thermo-mechanical history. Compared with those of the traditional extruder, better mechanical properties and finer dispersion particles have been achieved.

Core-shell impact modifiers, such as acrylic impact modifier $(\mathrm{ACR}),{ }^{27,28}$ acrylonitrile-butadiene-styrene (ABS) ${ }^{29}$ and methyl methacrylate-butadiene-styrene (MBS), ${ }^{30}$ are important types of toughener of PLA. Li et al. ${ }^{31}$ have reported that ACR with different core-shell ratios were synthesized and used to toughen PLA. The impact strength of PLA could be significantly improved by ACR. Sun et al..$^{32}$ have explored the use of GMAfunctionalized ABS (ABS-g-GMA) core-shell particles to
${ }^{b}$ Key Laboratory of Polymer Ecomaterials, Chinese Academy of Sciences, Changchun Institute of Applied Chemistry, Changchun 130022, China.E-mail: hlzhang@ciac.ac. cn

${ }^{c}$ University of Science and Technology of China, 230026, China 
toughen PLA. Zhang et $a l^{30}$ have reported that PLA was compatible with a core-shell of MBS and MBS could be used effectively as an impact modifier of PLA. ${ }^{8}$

Although NR, ENR, ACR, and MBS have a good toughening effect, they are non-biodegradable materials. And it will have harmful effects on the environment after application. However, the properties of PLA/PBAT blends have superior performance in the practical field, but the high cost of PBAT is disadvantage for the widespread application of PLA. Poly(propylene carbonate) (PPC) is also a biodegradable aliphatic polycarbonate, ${ }^{33}$ and the low cost of PPC is advantage for the widespread application of PLA. But the properties of PLA/PPC blends are insufficient for the widespread application of PLA, it can be seen in the past study. PPCU was prepared by using PPC and polyols as the raw materials and diphenyl-methanediisocyanate (MDI) as the extender chain. ${ }^{34}$

In the research here, PPCU was chosen to toughen PLA. PLA was blended with PPCU by internal mixer. The miscibility, mechanical properties, phase morphology, and crystallization behavior of PLA/PPCU blends were investigated. The impact strength and the elongation at break of PLA/PPCU were improved nearly 25 and 60 times in comparison with those of neat PLA.

\section{Experimental}

\section{Materials and preparation of the blends}

PLA Grade 4032 D (2\% D-lactide, 98\% L-lactide content) was obtained from Natureworks LLC (United States). The general molecular weight $\left(M_{\mathrm{w}}\right)$ average was about $2.07 \times 10^{5} \mathrm{~g} \mathrm{~mol}^{-1}$, polydispersity of 1.73 . Thermoplastic poly(propylene carbonate) polyurethane (PPCU) was purchased from Jiangsu Zhongke Jinlong Chemical Co., Ltd.

PLA and PPCU were dried at $70{ }^{\circ} \mathrm{C}$ for $8 \mathrm{~h}$ in a drying cabinet. First, PLA/PPCU blends were prepared by melt mixing with a Haake Rheomix 600 (Karlsruhe, Germany) at a rotating speed $60 \mathrm{rpm}$ at $190{ }^{\circ} \mathrm{C}$ for $5 \mathrm{~min}$. The mixing compositions of the PLA/PPCU blends were 100/0, 90/10, 80/20, 70/30, 60/40, and $50 / 50 \mathrm{w} / \mathrm{w}$. Then, all the samples and pure PLA were compression molded into sheets with thicknesses of 3.0 and $1.0 \mathrm{~mm}$ at $190{ }^{\circ} \mathrm{C}$ for impact strength measurement, tensile measurement, differential scanning calorimetry, dynamic mechanical analysis, phase morphology tests, rheological measurements.

\section{Characterization}

Structure analysis. The chemical structure of PPC and PPCU were analyzed with a Fourier transform infrared spectrophotometer (FTIR, Perkin Elmer, 2200, USA) with the wave number ranging from 4000 to $400 \mathrm{~cm}^{-1}$. The molecular weight of PPCU was measured by gel permeation chromatography (GPC, Waters 1515, USA), the eluent was tetramethylene oxide, and flow rate was $1.0 \mathrm{ml} \mathrm{min}{ }^{-1}$.

Mechanical testing. Notched Izod impact tests were performed at $23 \pm 2{ }^{\circ} \mathrm{C}$ according to ASTM D256-2010 on an impact testing machine (Changchun City Intelligent Instrument Equipment Co., Ltd., China). The samples with dimension $L \times$
$W \times H=80 \times 10 \times 3 \mathrm{~mm}^{3}$ were obtained from compressionmolded specimens. The notch was milled with a depth of $2.54 \mathrm{~mm}$, an angle of $45^{\circ}$, and a notch radius of $0.25 \mathrm{~mm}$. The uniaxial tensile tests were carried out at $23 \pm 2{ }^{\circ} \mathrm{C}$ on an Instron 1121 testing machine (Canton MA, USA). All tensile specimens were dumb-bell types with dimension $L \times W \times H=75 \times 4 \times$ $1 \mathrm{~mm}^{3}$. Samples were conditioned for at least 24 hours prior to testing at room temperature and $50 \%$ relative humidity controlled environment. The measurements were conducted at a crosshead speed of $50 \mathrm{~mm} \mathrm{~min}^{-1}$ at room temperature according to ASTM D638-2008. At least five runs for each sample were measured, and the results were averaged.

SEM. The fracture surfaces of PLA/PPCU blends from the impact and tensile tests were characterized by scanning electron microscopy (SEM) (model Japan JXA-840 ESEMFE, Japan). Micrographs of the cryogenically fracture surfaces of PLA/PPCU blends are also studied. A layer of gold was sputter-coated uniformly over all of the fractured surfaces before SEM observations.

DSC. Crystallization behavior of the blends was studied by differential scanning calorimetry (DSC) (TA Instruments DSC Q20, USA) on the specimens sliced from compression molded samples. The heating and cooling rates were $10{ }^{\circ} \mathrm{C} \mathrm{min}^{-1}$ with nitrogen purge, and the sample weights were between 5 and $8 \mathrm{mg}$. The samples were heated first from $20^{\circ} \mathrm{C}$ up to $195^{\circ} \mathrm{C}$ at $10{ }^{\circ} \mathrm{C} \mathrm{min}^{-1}$ and held at $195{ }^{\circ} \mathrm{C}$ for $3 \mathrm{~min}$ to eliminate their previous thermal history, then cooled from $195{ }^{\circ} \mathrm{C}$ up to $20^{\circ} \mathrm{C}$ at $10{ }^{\circ} \mathrm{C} \mathrm{min} \min ^{-1}$, and heated again from $20{ }^{\circ} \mathrm{C}$ up to $195{ }^{\circ} \mathrm{C}$ at $10{ }^{\circ} \mathrm{C} \min ^{-1}$.

The procedures for isothermal crystallization kinetic experiments were as follows: all samples were heated to $195{ }^{\circ} \mathrm{C}$ at $45{ }^{\circ} \mathrm{C} \mathrm{min}^{-1}$ and held for $3 \mathrm{~min}$ to eliminate the previous thermal history, and then cooled from $195{ }^{\circ} \mathrm{C}$ down to $90{ }^{\circ} \mathrm{C}$ at $45{ }^{\circ} \mathrm{C} \min ^{-1}$, until the crystallization was completed. After that, the samples were repeatedly heated to $195{ }^{\circ} \mathrm{C}$ at a rate of $45{ }^{\circ} \mathrm{C} \mathrm{min}^{-1}$, held for $3 \mathrm{~min}$. Then the samples cooled from $195{ }^{\circ} \mathrm{C}$ down to $94{ }^{\circ} \mathrm{C}, 98{ }^{\circ} \mathrm{C}, 102{ }^{\circ} \mathrm{C}$ and $106^{\circ} \mathrm{C}$ at $45^{\circ} \mathrm{C} \mathrm{min}^{-1}$, respectively, until the crystallization was completed.

Crystalline properties. Wide angle X-ray diffraction experiments were performed on a D8 advance X-ray diffractometer (Bruker, Germany) at room temperature in the range of $5-45^{\circ}$ at the scanning rate of $4^{\circ} \mathrm{min}^{-1}$. The $\mathrm{Cu} \mathrm{K} \alpha$ radiation $(\lambda=0.15418 \mathrm{~nm})$ source was operated at $40 \mathrm{kV}$ and $30 \mathrm{~mA}$.

Small-angle X-ray scattering (SAXS) experiments of undeformed specimens were performed at RT using a NanoSTAR-U (Bruker AXS Inc., Germany) with $\mathrm{Cu} \mathrm{K} \alpha$ radiation (wavelength, $\lambda=0.154 \mathrm{~nm}$ ). The generator was operated at $40 \mathrm{kV}$ and $650 \mu \mathrm{A}$. Two-dimensional SAXS patterns were obtained with a HI-STAR detector. The sample-to-detector distance was $L_{\mathrm{SD}}=$ $1074 \mathrm{~mm}$. The effective scattering vector $q(q=(4 \pi / \lambda) \sin \theta$, where $2 \theta$ is the scattering angle) at this distance ranged from 0.044 to $2.0 \mathrm{~nm}^{-1}$. The X-ray exposure time was $60 \mathrm{~min}$.

The crystallite morphology of PLA/PPCU blends was observed with a Leica DMLP polarized microscope (POM) (Wetzlar, Germany) equipped with a Linkam TM600 hot stage and a computer-controlled charged-coupled-device camera. A small amount of samples with the thickness of approximately 
$0.05 \mathrm{~mm}$ was sandwiched between two microscopic cover glasses and then placed on the hot stage. The samples were heated from room temperature to $190{ }^{\circ} \mathrm{C}$ at a rate of $30{ }^{\circ} \mathrm{C} \mathrm{min}^{-1}$, held at $190{ }^{\circ} \mathrm{C}$ for $3 \mathrm{~min}$ to eliminate previous thermal history, and then quenched to $120{ }^{\circ} \mathrm{C}$ at a rate of $30{ }^{\circ} \mathrm{C} \mathrm{min}{ }^{-1}$ for isothermal crystallization and held for $60 \mathrm{~min}$. The morphology changes were recorded during the crystallization process.

DMA. Dynamic mechanical analysis (DMA) was performed on a Netzsch DMA 242C (Selb, Germany), which provided the plots of the loss tangent $(\tan \delta)$ versus the storage modulus $\left(E^{\prime}\right)$. The size of the sample was $L \times W \times H=10 \times 5 \times 1 \mathrm{~mm}^{3}$. The experiment was performed in a tension mode at a constant heating rate of $3{ }^{\circ} \mathrm{C} \min ^{-1}$ and a frequency of $1 \mathrm{~Hz}$. The temperature ranged from 10 to $90{ }^{\circ} \mathrm{C}$ for PLA/PPCU samples.

Enzymatic degradation. The enzymatic degradation of the blends was carried out in phosphate (Tris-HCl buffered) buffer $\left(\mathrm{pH}=8.0\right.$ ) containing $0.2 \mathrm{mg} \mathrm{ml}^{-1}$ of proteinase $\mathrm{K}$ (Genview) at $45{ }^{\circ} \mathrm{C}$ with shaking at $140 \mathrm{rpm}$. The blends from the pressed sheets with thicknesses of $0.1 \mathrm{~mm}$ were chopped into square with gauge dimensions of $10 \mathrm{~mm} \times 10 \mathrm{~mm}$. Then all samples were placed in small glass bottles containing the buffer and proteinase $\mathrm{K}$. The samples were picked up after a fixed time interval, washed with distilled water, and dried to constant weight in a vacuum, and then the weights of the blends were measured. For each polymer sample, five blends were used, and the average value of their weight loss was reported.

\section{Results and discussion}

\section{Structure analysis}

FT-IR spectra of PPC and PPCU were displayed in Fig. 1. It was seen that the band corresponding to the terminal hydroxy bonds of PPC at $3420 \mathrm{~cm}^{-1}$ disappeared, and new bands corresponding to the $\mathrm{NH}$ and NHCO bonds appeared at 3340 and $1592 \mathrm{~cm}^{-1}$, respectively. ${ }^{35}$ The structure diagram of PPCU was exhibited as Scheme 1. In Fig. 2, it indicated that the weightaverage molecular weight of PPCU was $M_{\mathrm{w}}=1.595 \times$ $10^{5} \mathrm{~g} \mathrm{~mol}^{-1}$, and polydispersity was 1.13 from gel permeation chromatography analysis.

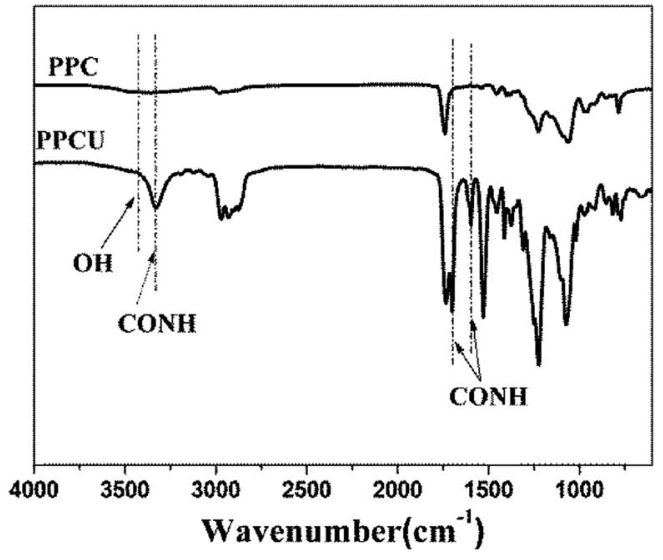

Fig. 1 FT-IR spectra of PPC and PPCU.

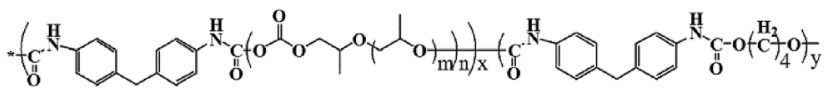

Scheme 1 The structure of PPCU.

\section{Mechanical properties}

Fig. 3 showed the notched Izod impact strength, tensile strength and elongation at break of PLA/PPCU blends, it indicated that the toughness of PLA was improved with the addition of PPCU. The notched impact strength of pure PLA was about $4.8 \mathrm{~kJ} \mathrm{~m}^{-2}$. From Fig. 3(a), it was shown that there was no obvious improvement of impact strength for the 90/10 PLA/ PPCU blend. However, with the further increase of PPCU content from 10 to $50 \mathrm{wt} \%$ in the PLA/PPCU blends, the notched impact strength of the blends was significantly improved from $5.4 \mathrm{~kJ} \mathrm{~m}^{-2}$ to $102.8 \mathrm{~kJ} \mathrm{~m}^{-2}$. The brittle-ductile transition of the blends was obtained when the PPCU contents varied from 10 to $20 \mathrm{wt} \%$.

The impact strength, Young's modulus, tensile strength, and elongation at break of PLA/PPCU blends were summarized in Table 1. It indicated that the brittle properties of PLA could be modified by the addition of PPCU. The elongation at break of pure PLA was about $7.3 \%$, whereas the elongation at break of 50/50 PLA/PPCU blend was about $457.9 \%$. The elongation at break of 50/50 PLA/PPCU blends was improved nearly 60 times in comparison with that of pure PLA. These results also indicated that the PPCU could significantly improve the mechanical properties of PLA.

Fig. 4 shows tensile stress-strain curves of PLA/PPCU, pure PLA was brittle fracture, and the PLA/PPCU blends generated shear yield when the PPCU contents was $10 \%$. In the other word, the brittle-ductile transition of the blends was obtained after in addition of PPCU. The yield strength of PLA/PPCU blends decreased continuously with increasing PPCU content. This addicted that the brittle of PLA had been weaken and the toughness been greatly enhanced.

\section{Toughening mechanism}

Scanning electron microscopy (SEM) was used to investigate the toughening mechanism of PLA/PPCU blends. The SEM

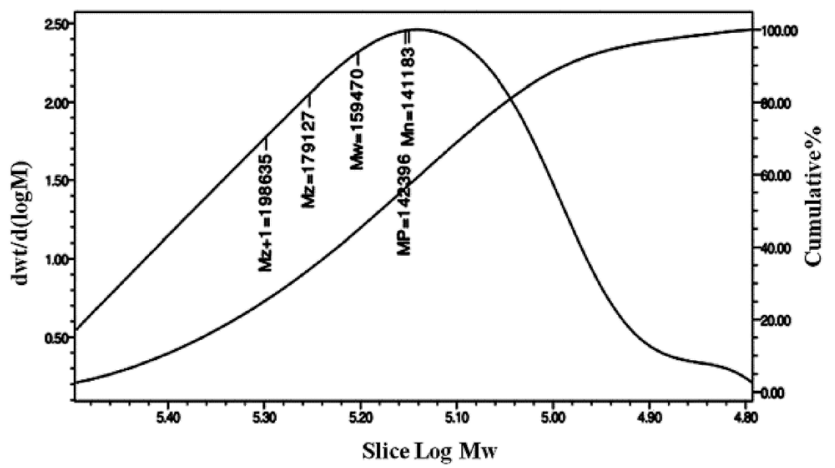

Fig. 2 Molecular weight distribution of PPCU. 

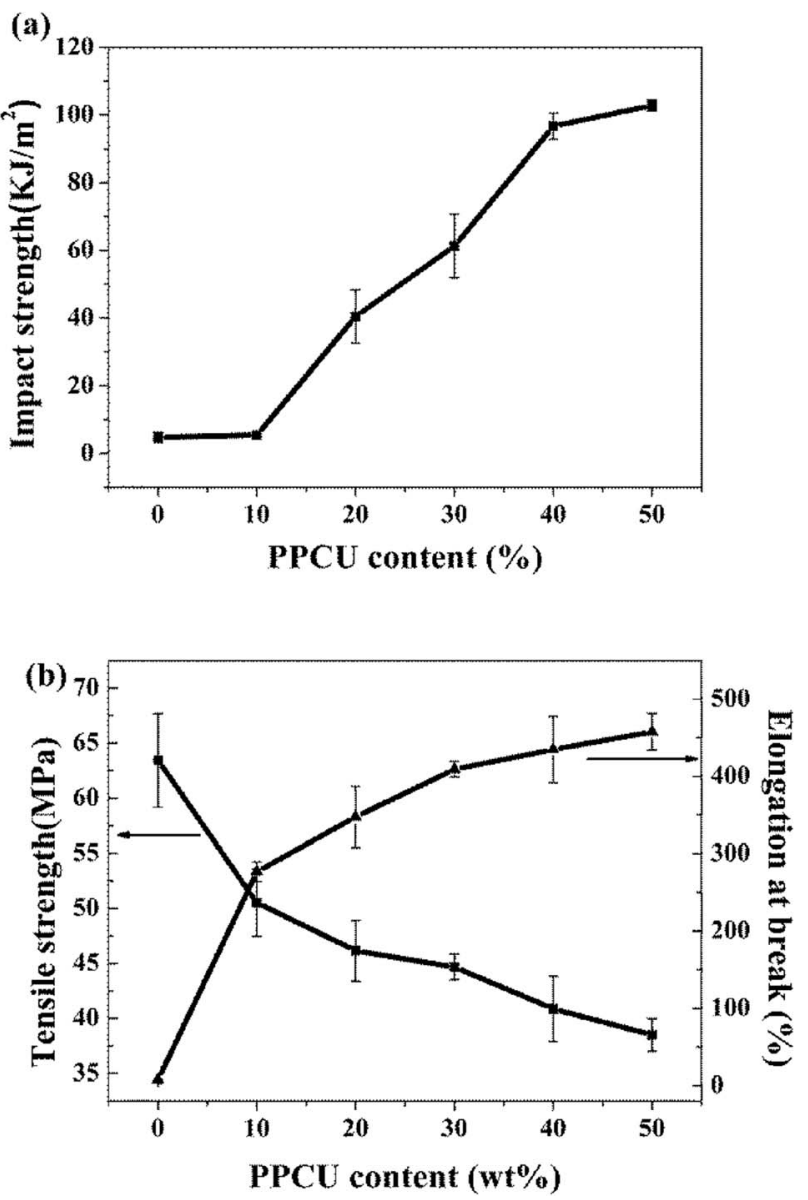

Fig. 3 The Mechanical properties of PLA/PPCU blends (a) Impact strength, (b) Tensile strength and elongation at break.

photographs were shown in Fig. 5. The impact fracture surfaces of PLA/PPCU blends were observed by using SEM. From Fig. 5(a-f), the impact fracture surface of pure PLA showed relatively smooth, indicating that little shear yielding had taken place during the impact test. This was in agreement with low impact strength of pure PLA. ${ }^{31}$ From Fig. 5(c), as the PPCU content of PLA/PPCU reached $20 \mathrm{wt} \%$, rough surface could be seen on the fracture surface of PLA/PPCU blend. This was consistent with the results of the impact strength of the blends. The fracture surface of PLA/PPCU blend was different from other photographs. Obvious many root-like whiskers and many long stretches of the ligaments structure could be seen on the

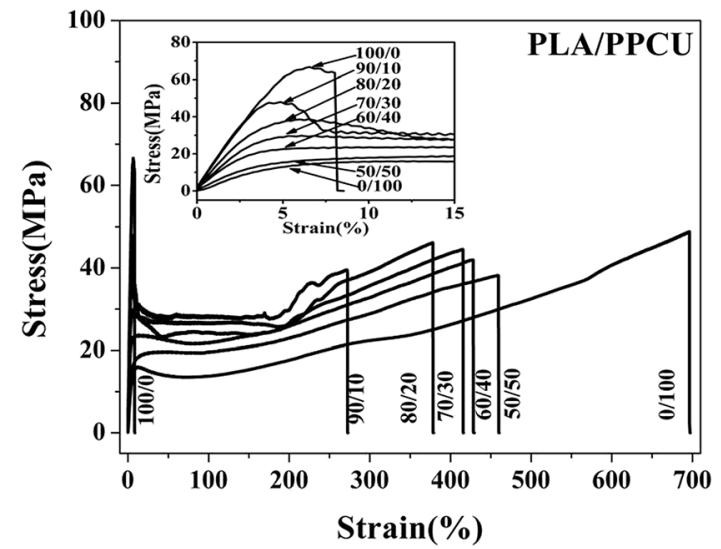

Fig. 4 The tensile stress-strain curves of PLA/PPCU.

fracture surface of the 80/20 and 70/30 PLA/PPCU blends. From Fig. 5(d) and (e), more obvious filiform structure could be seen on fracture surface of PLA/PPCU blends with further increasing PPCU content from 40 to $50 \mathrm{wt} \%$.

From Fig. 6, obvious cavities could be seen on the PLA/PPCU blends. Bucknall et al. ${ }^{36}$ had reported that elastomeric play two roles: first, as a stress concentration induced a large amount of silver lines and shear zone. Second, control the silver grain development and make silver grain into destructive crack timely termination without development. Cavitations are important in notched specimens because it enables the blend to yield at moderate stresses under plane strain conditions. The cavities were formed because that two-phase's surface had debonded between PLA and PPCU when the blends were pulled out. To study the toughening mechanism of PLA/PPCU blends, the necked down region of the tensile specimen was cryo-fractured longitudinally. ${ }^{8}$ SEM micrographs of fractured surfaces were shown in Fig. 6. The micrographs of the tensile specimen were taken at different locations of the necked down region as depicted in Fig. 6(a), where the stress state varied. The materials which had no necking in the tensile test demonstrated a smooth longitudinal fracture surface without visible plastic deformation in Fig. 6(b). Some obvious cavities could be seen on the PLA/PPCU blends. The cavities had been observed when the PPCU phase was pulled out from the PLA matrix due to debonding. In Fig. 6(c) and (d), oval cavities were visible near the necked down region of the PLA/ PPCU blends during tension where enlarging stresses were created. These cavities were formed when the volumetric strain

Table 1 The mechanical properties of PLA/PPCU

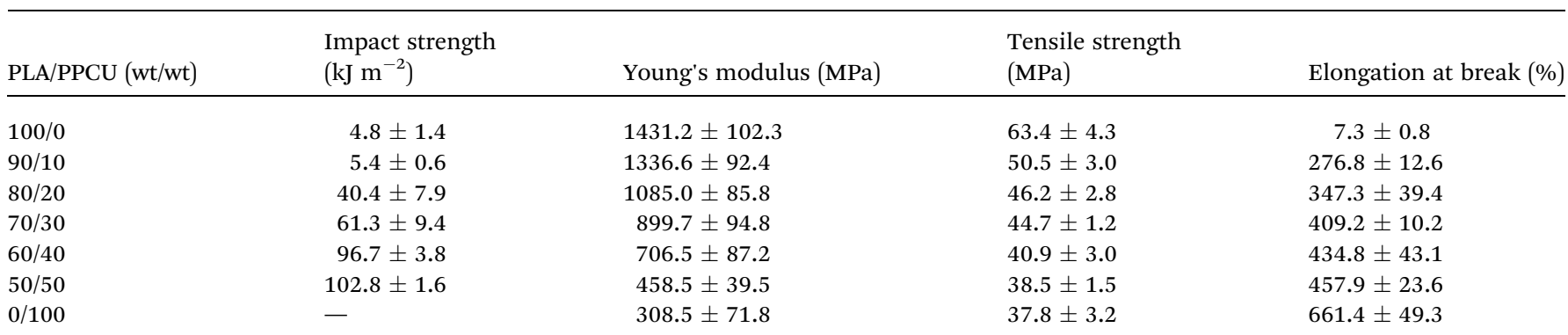



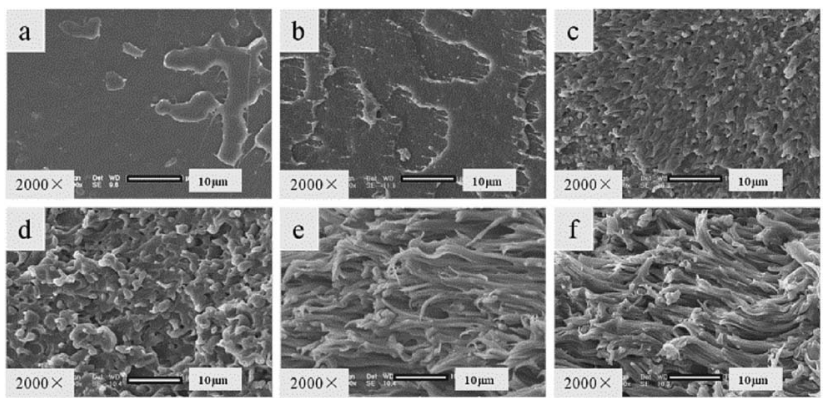

Fig. 5 SEM photographs of the impact fracture surface of PLA/PPCU blends. (a) Pure PLA, (b) PLA/PPCU 90/10, (c) 80/20, (d) 70/30, (e) 60/ 40 and (f) $50 / 50$.

energy released by forming a void was greater than the surface energy needed to form new surface plus the energy needed to stretch the surrounding elastomeric particles to make space for the void. ${ }^{26}$ These cavities were enlarged in the stress direction along with the deformation of the matrix. It indicated that shear yielding occurred in the PLA matrix as induced by the cavitation of PPCU particles was the major toughening-mechanism.

\section{Thermal properties}

Differential scanning calorimetry (DSC) heating thermograms of samples were shown in Fig. 7, and the corresponding parameters for the PLA/PPCU blends were summarized in Table 2 .

As shown in Fig. 7, three main transitions successively could be observed: a glass transition, a cold crystallization exotherm and a melting endotherm. It could be seen that pure PLA exhibited a glass transition at $63.2^{\circ} \mathrm{C}$. The addition of PPCU had taken place a marked change in the glass transition temperature of PLA. The addition of PPCU decreased the glass transition temperature from 63.2 ${ }^{\circ} \mathrm{C}$ for pure PLA to $58.7^{\circ} \mathrm{C}$ for the 50/50 PLA/PPCU blend.

The absolute degree of crystallinity $\left(X_{\mathrm{c}}\right)$ of the samples was evaluated from the heat evolved during crystallization by the following relationship (eqn (1)):
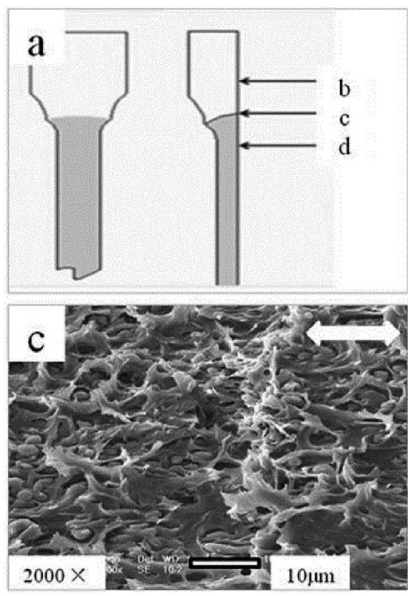
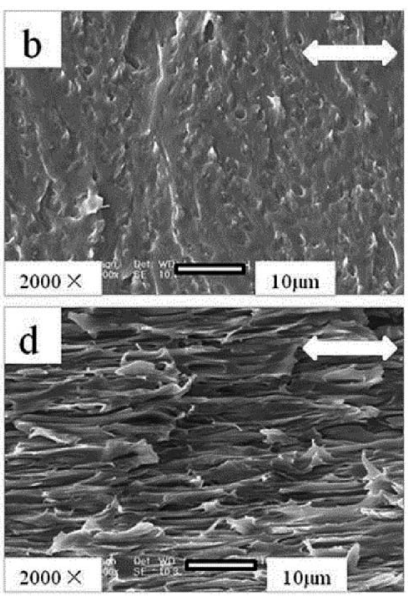

Fig. 6 SEM micrographs of PLA/PPCU $70 / 30$ blend during tensile testing.

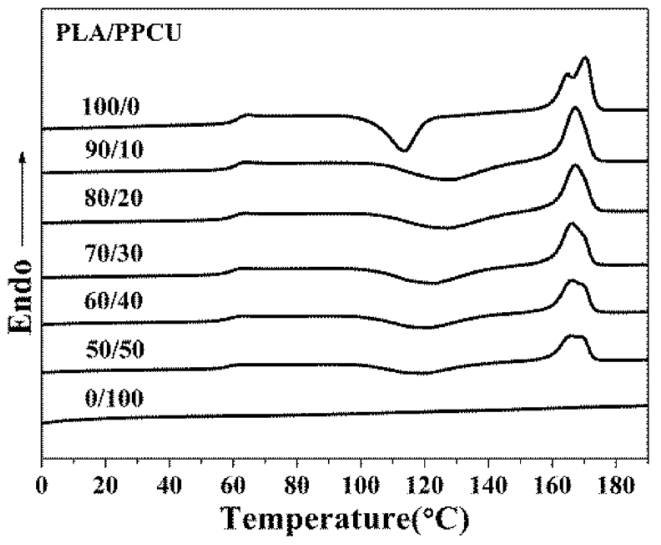

Fig. 7 DSC thermograms recorded during the second heating run for pure PLA and PLA/PPCU blends.

$$
X_{\mathrm{C}}(\%)=\frac{\Delta H_{\mathrm{f}}}{W_{\mathrm{PLA}} \times \Delta H_{\mathrm{f}}^{0}} \times 100
$$

where $X_{\mathrm{c}}$ is the degree of crystallinity of the PLA, $\Delta H_{\mathrm{f}}$ is the heat of fusion of the PLA in the blend, $\Delta H_{\mathrm{f}}^{0}$ is the heat of fusion for $100 \%$ crystalline PLA $\left(93 \mathrm{~J} \mathrm{~g}^{-1}\right)^{37}$ and $W_{\text {PLA }}$ is the weight fraction of PLA in the blend.

From Fig. 7, pure PLA exhibited a cold crystallization temperature at $113.6{ }^{\circ} \mathrm{C}$. The addition of PPCU increased the cold crystallization temperature from $113.6{ }^{\circ} \mathrm{C}$ for pure PLA to 119.0 ${ }^{\circ} \mathrm{C}$ for the 50/50 PLA/PPCU blend. It was therefore demonstrated that the addition of PPCU made it easier for PLA to crystallize. It indicated that PPCU could improve the crystallization temperature for PLA. But the positive function of crystallization was weaken when the content of PPCU further increasing. The process could be expressed as Scheme 2, and the content of PPCU gradually increasing from a to $d$. It could be seen that before the melting peak was accompanied by a small exothermic peak for pure PLA. It was generated the metastable $\alpha^{\prime}$-form crystal because the cold crystallization of PLA occurred in the temperature range lower than $T_{\text {critical }}$ (approximately $120{ }^{\circ} \mathrm{C}$ ) temperature range. The $\alpha^{\prime}$-form would be transformed into more stable $\alpha$-form crystal when heated to high temperature (approximately $165^{\circ} \mathrm{C}$ ), $\alpha^{\prime}-\alpha$ phase transition leading to the generation of the exothermic peak. It could be seen from the Fig. 7, the double melting peak moved from high to low temperatures with increasing PPCU content. It indicated that the addition of PPCU main effect was to promote the formation of $\alpha^{\prime}$-form crystal.

The effect of PPCU on the ability of PLA to crystallize could be further confirmed from the low heat of fusion $\left(\Delta H_{\mathrm{f}}\right)$ of the PLA/PPCU blends in comparison to that of pure PLA (Table 2). However, the value of $W_{\text {PLA }} \times$ decreased faster comparing to that of $\Delta H_{\mathrm{f}}$ with increasing PPCU content in the blends, the result suggesting that PPCU enhanced the crystallinity of PLA. The value of $\Delta H_{\mathrm{f}}$ decreased, indicated that the crystallinity of blends was decreasing with increasing PPCU content in the blends. It also indirectly indicated that the PLA/PPCU blends had obtained higher toughness. 
Table 2 Crystallization properties of PLA/PPCU blends obtained from second heating run

\begin{tabular}{|c|c|c|c|c|c|c|}
\hline PLA/PPCU (wt/wt) & $T_{\mathrm{g}}\left({ }^{\circ} \mathrm{C}\right)$ & $T_{\mathrm{cc}}\left({ }^{\circ} \mathrm{C}\right)$ & $\Delta H_{\mathrm{cc}}\left(\mathrm{J} \mathrm{g}^{-1}\right)$ & $X_{\mathrm{c}}(\%)$ & $T_{\mathrm{m}}\left({ }^{\circ} \mathrm{C}\right)$ & $\Delta H_{\mathrm{f}}\left(\mathrm{J} \mathrm{g}^{-1}\right)$ \\
\hline $100 / 0$ & 63.2 & 113.6 & 32.3 & 40.6 & 170.3 & 37.8 \\
\hline $90 / 10$ & 61.2 & 128.0 & 31.0 & 41.2 & 167.3 & 34.5 \\
\hline $70 / 30$ & 60.1 & 122.9 & 25.2 & 44.2 & 166.2 & 28.8 \\
\hline $60 / 40$ & 59.6 & 121.0 & 20.7 & 43.9 & 166.2 & 24.5 \\
\hline $50 / 50$ & 58.7 & 119.0 & 15.0 & 40.6 & 165.8 & 18.9 \\
\hline
\end{tabular}

\section{Isothermal crystallization kinetics}

The well-known Avrami equation ${ }^{38,39}$ was used to analyze the remarkable overall isothermal crystallization kinetics of blend samples. It assumes that the relative crystallinity $X(t)$ develops as a function of crystallization time $t$ as follows:

$$
X(t)=1-\exp \left(-K t^{n}\right)
$$

The Avrami equation could be further deduced as,

$$
\lg [-\ln (1-X(t))]=\lg K+n \lg t
$$

where $n$ is the Avrami exponent and $K$ is the overall kinetic rate constant. Both $n$ and $K$ depend on the mechanism of the nucleation as well as the growth geometry. The double logarithmic plots of the Avrami analysis for all samples are shown in Fig. 8. From the figure, it can be seen that the experimental data fit well with the Avrami equation, for PLA/PPCU blends and pure PLA; plots of $\lg [-\ln (1-X(t))]$ versus $\lg t$ result in a linear relationship. From the slope and intercept of the curves, the Avrami exponent $n$ and rate constant $K$ can be obtained, and the value of $n$ and $K$ was enumerated in Table 3 .

For pure PLA sample, the $n$ values observed in the present work were around 2.5-2.8. For the 90/10, 80/20, and 70/30 PLA/ PPCU blends, the $n$ values were between 2.3 and 3.0, which suggested that the 90/10, 80/20, and 70/30 PLA/PPCU blends have a stronger trend of instantaneous three-dimensional growth than pure PLA. The other $n$-values of the $60 / 40$ and 50/50 PLA/PPCU blends are between 2.0 and 2.6.

Wunderlich ${ }^{\mathbf{4 0}}$ had attributed an Avrami $n$ exponent of 3 to spherical structure resulting from instantaneous nucleation (that is, the number of nuclei reaches a steady state value rapidly after crystallization begins) and an exponent $n$ between 2 and 3 to truncated spheres resulting from instantaneous nucleation with diffusion control. This fact indicates that the

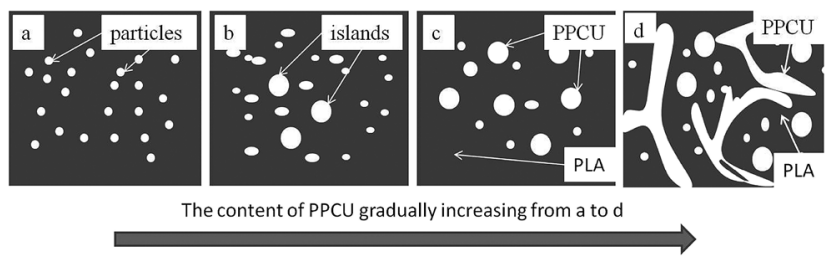

Scheme 2 A small number of particles to promote crystallinity mechanism. incorporation of the PPCU content is larger than $40 \%$, and PPCU can be used as a amorphous polymer that impede the diffusion of PLA macromolecular chains. The overall rate constant $K$ is extremely sensitive to temperature, which determines both the nucleation and the growth processes. The $K$ values of all the samples decrease with increase in the crystallization temperature, and this means both the nucleation rate and growth rate decrease as the crystallization temperature increases. However, at the same crystallization temperature, all of the PLA/PPCU blends have lower $K$ values than pure PLA, which also indicates that an addition of PPCU in PLA decreases the crystallization rate of PLA.

For all samples, the effect of PPCU on the crystallization rate $K$ (Table 3), the inclusion of PPCU significantly decreased the crystallization rates of the PLA/PPCU blends, compared to the pure PLA.

Meanwhile, $t_{1 / 2}$ can be determined from the measured kinetic parameters according to the following equation: ${ }^{\mathbf{4 1}}$
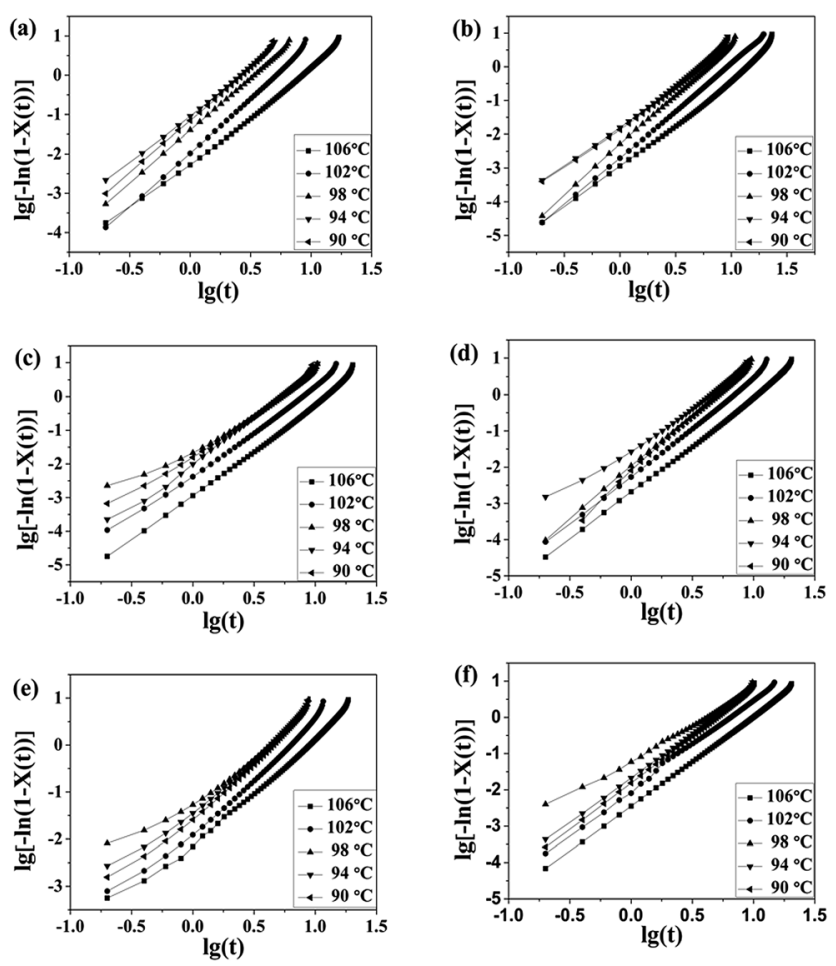

Fig. 8 Plots of $\lg \{-\ln [1-X(t)]\}$ versus $\lg t$ for isothermal crystallization at the indicated temperatures: (a) pure PLA, (b) PLA/PPCU 90/10, (c) 80/20, (d) 70/30, (e) 60/40, (f) 50/50. 
Table 3 Kinetic parameters for isothermal crystallized PLA/PPCU blends obtained from Avrami equation

\begin{tabular}{|c|c|c|c|c|c|c|}
\hline PLA/PPCU (wt/wt) & $T_{\mathrm{c}}\left({ }^{\circ} \mathrm{C}\right)$ & $K$ & $n$ & $t_{1 / 2}(\min )$ & $t_{\max }(\min )$ & $g$ \\
\hline \multirow[t]{5}{*}{$100 / 0$} & 106 & 0.005 & 2.5 & 7.17 & 14.08 & 0.14 \\
\hline & 102 & 0.010 & 2.8 & 4.43 & 9.01 & 0.23 \\
\hline & 98 & 0.039 & 2.7 & 2.93 & 5.89 & 0.34 \\
\hline & 94 & 0.097 & 2.5 & 2.40 & 4.82 & 0.42 \\
\hline & 90 & 0.072 & 2.7 & 2.30 & 4.64 & 0.43 \\
\hline \multirow[t]{5}{*}{$90 / 10$} & 106 & 0.001 & 2.7 & 11.85 & 23.89 & 0.08 \\
\hline & 102 & 0.002 & 2.8 & 8.11 & 16.48 & 0.12 \\
\hline & 98 & 0.005 & 3.0 & 5.44 & 11.15 & 0.18 \\
\hline & 94 & 0.016 & 2.6 & 4.83 & 9.60 & 0.21 \\
\hline & 90 & 0.014 & 2.6 & 4.58 & 9.08 & 0.22 \\
\hline \multirow[t]{5}{*}{$80 / 20$} & 106 & 0.001 & 2.8 & 10.38 & 21.11 & 0.10 \\
\hline & 102 & 0.004 & 2.7 & 6.73 & 13.54 & 0.15 \\
\hline & 98 & 0.025 & 2.3 & 4.89 & 10.20 & 0.20 \\
\hline & 94 & 0.008 & 2.9 & 4.57 & 9.35 & 0.22 \\
\hline & 90 & 0.017 & 2.5 & 4.34 & 8.56 & 0.23 \\
\hline \multirow[t]{5}{*}{$70 / 30$} & 106 & 0.002 & 2.7 & 9.18 & 18.49 & 0.11 \\
\hline & 102 & 0.005 & 2.8 & 5.96 & 12.05 & 0.17 \\
\hline & 98 & 0.010 & 2.8 & 4.49 & 9.14 & 0.22 \\
\hline & 94 & 0.031 & 2.4 & 3.72 & 9.05 & 0.27 \\
\hline & 90 & 0.007 & 3.0 & 3.45 & 8.15 & 0.29 \\
\hline \multirow[t]{5}{*}{$60 / 40$} & 106 & 0.010 & 2.2 & 7.14 & 12.87 & 0.14 \\
\hline & 102 & 0.013 & 2.4 & 5.24 & 10.08 & 0.19 \\
\hline & 98 & 0.064 & 2.0 & 4.34 & 8.62 & 0.23 \\
\hline & 94 & 0.041 & 2.3 & 3.50 & 7.53 & 0.29 \\
\hline & 90 & 0.029 & 2.4 & 3.27 & 7.26 & 0.31 \\
\hline \multirow[t]{5}{*}{$50 / 50$} & 106 & 0.003 & 2.5 & 8.40 & 16.51 & 0.12 \\
\hline & 102 & 0.017 & 2.2 & 5.33 & 9.85 & 0.19 \\
\hline & 98 & 0.109 & 2.3 & 4.99 & 8.06 & 0.20 \\
\hline & 94 & 0.021 & 2.5 & 4.04 & 7.96 & 0.25 \\
\hline & 90 & 0.015 & 2.6 & 3.32 & 7.63 & 0.30 \\
\hline
\end{tabular}

$$
t_{1 / 2}=(\ln 2 / K)^{1 / n}
$$

The overall crystallization rate $(G)$ calculated from the reciprocal of crystallization half time is listed in Table 3 as well.

$$
G=1 / t_{1 / 2}
$$

It is clearly observed that the trend of $G$ is similar to that of $K$. In Table 3, the result of isothermal crystallization kinetic indicated that the values of $t_{1 / 2}$ of PLA/PPCU blends increasing after in addition of PPCU, compared to the pure PLA. It can be explained that the PLA was dispersed and impeded by high content of PPCU, and the crystallization ability of blends was weaken. But the values of $t_{1 / 2}$ were gradually decreased with increasing PPCU content from 10 to $50 \mathrm{wt} \%$. It indicated that PPCU could improve the crystallization rate of PLA when the PPCU content varied from 10 to $50 \mathrm{wt} \%$. It was further verified for the trend of $G$ value. In one word, the crystallization degree of PLA/PPCU blends was decreased with the addition of PPCU, and embodied in improving the toughness of PLA.

\section{Crystalline morphology}

As a semicrystalline polymer, the crystal structure and morphology of PLA have been extensively investigated using many techniques from the academic viewpoint of structural interest. X-ray diffraction is one of the most accurate and representative techniques. It has been reported that PLA crystallizes in seven forms $\left(\alpha, \alpha^{\prime}, \alpha^{\prime \prime}, \beta, \gamma, \varepsilon\right.$, and stereo complex $),{ }^{42}$ the formation of which depends on the crystallization conditions. The most common $\alpha$-form occurred in conventional melt and solution crystallization conditions. Therefore, to get further information about the crystal morphologies of pure PLA and PLA/PPCU blends, wide-angle X-ray diffraction experiment was performed in this study. Fig. 9 showed the WAXD patterns of pure PLA and PLA/PPCU blends. Curves are expressed to those crystallized isothermally at $120{ }^{\circ} \mathrm{C}$ for $1 \mathrm{~h}$. Certainly, it is enough to complete the crystallization processes of PLA samples at $120^{\circ} \mathrm{C}$. The most representative peaks of the $\alpha$-form crystals can be observed at diffraction angles $2 \theta$ of 14.8 (010), 16.7 (200), 19.0 (203), 22.3 (213), indicating that PLA is the typical orthorhombic crystal. It can be seen that the incorporation of PPCU does not alter the crystal structure of the PLA matrix. Wu et al. ${ }^{43}$ reported that the pure PLA isothermally crystallized by cooling in the air showing three small characteristic peaks, indicating that the sample is almost amorphous (low crystallinity) attribute to the low homogeneous crystallization rate during the rapid-cooling treatment. However, when the PLA samples are isothermally crystallized at $120^{\circ} \mathrm{C}$ for $1 \mathrm{~h}$, four distinct diffraction peaks at 14.8 (010), 16.7 (200), 19.0 (203) and 22.3 (213) are appeared. The most common explanation for this phenomenon is that the isothermal crystallization at a suitable temperature can contribute to the formation of the lamella, thus the crystals are likely more perfect of lager size or lamella thickness, better organized spherulites and increase of crystallinity. These above results suggest that the formation of perfect $\alpha$-form crystals may be related to additives component, crystallization temperature, and time employed. ${ }^{43}$

Fig. 9 shows the WAXD patterns for the pure PLA and PLA/ PPCU blends. It can be seen that the incorporation of PPCU does not change the crystal structure of PLA in the blends relative to the pure PLA. The degree of crystallinity of PLA was calculated as eqn (6):

$$
W_{\mathrm{c}, \mathrm{x}}=\frac{\sum_{i} C_{i, h k l}(\theta) I_{i, h k l}(\theta)}{\sum_{i} C_{i, h k l}(\theta) I_{i, h k l}(\theta)+k_{i} C_{\mathrm{a}}(\theta) I_{\mathrm{a}}(\theta)} \times 100 \%
$$

where $W_{\mathrm{c}, \mathrm{x}}$ is the degree of crystallinity, $I_{i, h k l}(\theta)$ and $I_{\mathrm{a}}(\theta)$ are the relative intensities of the crystalline and amorphous peaks, respectively, and $C_{i, h k l}(\theta)$ and $C_{\mathrm{a}}(\theta)$ are the correction factors of the crystalline and amorphous peaks, respectively. ${ }^{44}$ On the basis of the X-ray diffraction intensity theory, $K$ is the total correction factor, $\left[K=C_{\mathrm{a}}(\theta) \times k_{i}\right.$, where $k_{\mathrm{i}}$ is the relative scattering coefficient, which is a ratio of calculated diffraction intensity $\left(\sum I_{i \text {,cal }}\right)$ to total scattering intensity $\left(\sum I_{i \text {,total }}\right)$ for unit weight of crystalline polymer, and $\left.k_{i}=\sum I_{i \text {,cal }} / \sum I_{i \text {,total }}\left(k_{i} \leq 1\right)\right]$. Here, $C_{i, h k l}(\theta)$ or $C_{\mathrm{a}}(\theta)$ can be calculated by the following equation:

$$
\begin{aligned}
C_{i, h k l(\theta)}{ }^{-1} \text { or } C_{\mathrm{a}}^{-1}(\theta) & =f^{2} \frac{1+\cos ^{2} 2 \theta}{\sin ^{2} \theta \cos \theta} \mathrm{e}^{-2 B(\sin \theta / \lambda)^{2}} \\
& =\sum_{i} N_{i} f_{i}^{2} \frac{1+\cos ^{2} 2 \theta}{\sin ^{2} \theta \cos \theta} \mathrm{e}^{-2 B(\sin \theta / \lambda)^{2}}
\end{aligned}
$$


(a)

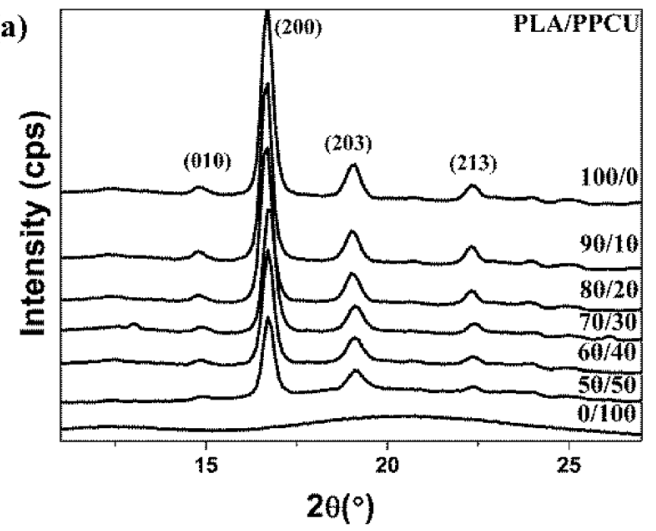

(b)

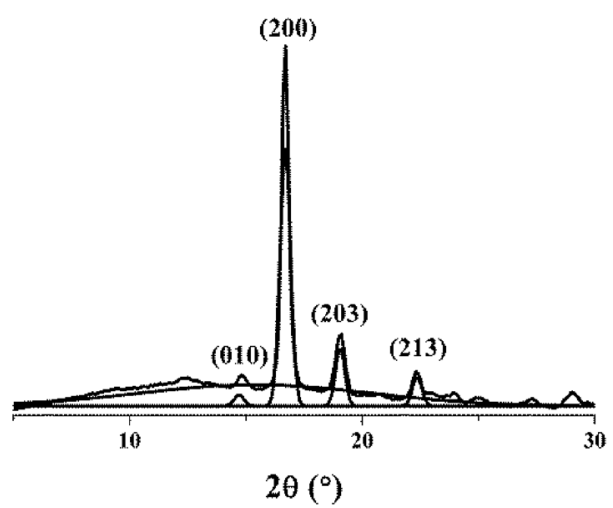

(c)

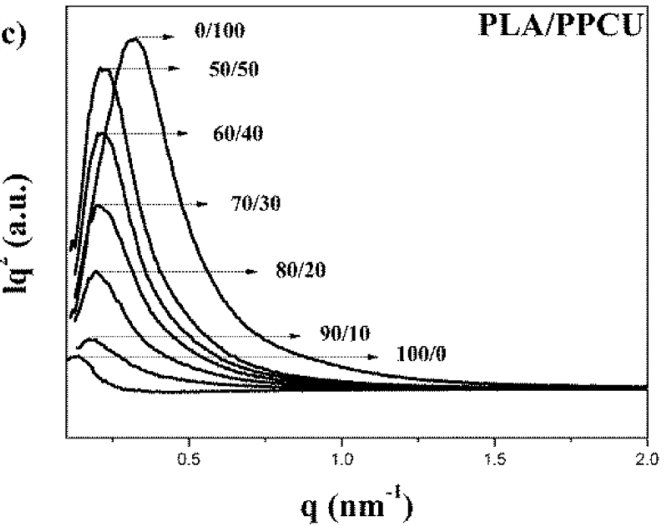

Fig. 9 Crystal X-ray analysis: (a) WAXD patterns of pure PLA and PLA/ PPCU blends isothermally crystallized at $120{ }^{\circ} \mathrm{C}$ for $1 \mathrm{~h}$, (b) magnification of the WAXD curve of PLA for the crystalline and amorphous portions, (c) Lorentz-corrected SAXS curves of pure PLA and PLA/ PPCU blends

where $f$ is the atomic scattering factor for one crystallographic structural repeating unit, $f_{i}$ is the scattering factors of the ith atom, $N_{i}$ is the number of ith atoms in a repeating unit, $2 \theta$ is the Bragg angle, the angle factor $(\mathrm{LP})=\left(1+\cos ^{2} 2 \theta\right) / \sin ^{2} \theta \cos \theta$, the temperature factor $(T)=\mathrm{e}^{-2 B(\sin \theta / \lambda)^{2}}$, and $2 B=10 . f_{i}$ can be expressed approximately by

$$
f_{i}(\sin \theta / \lambda)=\sum_{i=1}^{4} a_{i} \mathrm{e}^{-b_{i}(\sin \theta / \lambda)^{2}}+C
$$

Table 4 X-ray diffraction data of pure PLA

\begin{tabular}{llllll}
\hline$h k l$ & $\mathrm{~A}$ & 010 & 200 & 203 & 213 \\
$2 \theta$ & 16.1 & 14.8 & 16.7 & 19 & 22.3 \\
$I_{\mathrm{a}}(\theta)$ or $I_{i, h k l}(\theta)$ & 28831 & 1295 & 9000 & 5016 & 2484 \\
$I$ & 25947.9 & 1043.6 & 9908.7 & 7856.4 & 6235.2 \\
$T$ & 0.92 & 0.93 & 0.92 & 0.85 & 0.85 \\
$f^{2}=12 f_{\mathrm{H}}{ }^{2}+12 f_{\mathrm{C}}{ }^{2}+4 f_{\mathrm{O}}{ }^{2}$ & 193.9 & 200.0 & 191.0 & 179.6 & 162.9 \\
$\mathrm{LP}$ & 99.0 & 117.6 & 91.9 & 70.5 & 50.6 \\
$\mathrm{C}(\theta)$ & 1.0 & 0.8 & 1.1 & 1.6 & 2.5 \\
$K$ & 0.9 & & & &
\end{tabular}

where the values of $a, b$, and $C$ are given in ref. 44 .

The total WAXD curve of pure PLA was resolved into crystalline and amorphous portions (Fig. 9). From eqn (6)-(8), the X-ray diffraction data of the PLA/PPCU blends are shown in Table 4. $I_{h k l}=C_{i, h k l}(\theta) I_{i, h k l}(\theta)$ or $C \mathrm{a}(\theta) I_{\mathrm{a}}(\theta)$ is the integrating intensity scattered over a suitable angular interval by the crystalline and the amorphous phases, respectively. There are 3 atoms of carbon, 4 atoms of hydrogen, and 2 atoms of oxygen in a repeating unit of PLA; the total atomic scattering factor was $f_{h k l}{ }^{2}=3 f_{\mathrm{C}}{ }^{2}+4 f_{\mathrm{H}}{ }^{2}+2 f_{\mathrm{O}}{ }^{2}$, where $k_{i}=0.9, C_{\mathrm{a}}(\theta)=1$, and $K=$ $k_{i} C_{\mathrm{a}}(\theta)=0.9$. With the data of Table 4 , eqn (6) can be reduced to give eqn (9).

$$
W_{\mathrm{c}, \mathrm{x}}=\frac{0.8 I_{010}+1.1 I_{200}+1.6 I_{203}+2.5 I_{213}}{0.8 I_{010}+1.1 I_{200}+1.6 I_{203}+2.5 I_{213}+I_{\mathrm{a}}}
$$

where $I_{\mathrm{a}}$ is the intensity of amorphous peak. The degree of crystallinity $\left(W_{\mathrm{c}, \mathrm{x}}\right)$ for the pure PLA and PLA/PPCU blends was calculated with the eqn (9), the values shown in the Table 5, which the crystallinity values in Table 2 exhibited $W_{\mathrm{c}, \mathrm{x}}>X_{\mathrm{c}}$. The crystallinity determined from X-ray diffraction $\left(W_{\mathrm{c}, \mathrm{x}}\right)$ was equal to the sum of the crystalline and interphase contents, while the measurement of fusion enthalpy by calorimetry $\left(X_{\mathrm{c}}\right)$ yields values which were equal to the crystalline content. Imperfections of crystals were not easily distinguished from the amorphous phase. Therefore, some disagreements among the quantitative results of crystallinity by different measurement methods were frequently encountered. ${ }^{18}$

SAXS was used to investigate the crystal structure and macrostructure of neat PLA before and after blending with PPCU. Fig. 9 shows the Lorentz-corrected SAXS curves of the blends at various compositions annealed at $120^{\circ} \mathrm{C}$ for $1 \mathrm{~h}$.

The long spacing $d_{\mathrm{ac}}$, which was defined as the crystal layer thickness together with one interlamellar amorphous layer, measured along the lamella normal and calculated using Bragg eqn (6). ${ }^{44}$

The crystal layer thickness $d_{\mathrm{c}}$ and the amorphous layer thickness $d_{\mathrm{a}}$ can be calculated using eqn (11) and (12), respectively.

$$
\begin{array}{r}
d_{\mathrm{ac}}=\frac{2 \pi}{q_{\mathrm{max}}} \\
d_{\mathrm{c}}=d_{\mathrm{ac}} \times X_{\mathrm{c}} \\
d_{\mathrm{a}}=d_{\mathrm{ac}}-d_{\mathrm{c}}
\end{array}
$$


Table 5 X-ray degree of crystallinity for the PLA/PPCU blends from isothermally crystallized at $120^{\circ} \mathrm{C}$ for $1 \mathrm{~h}$

\begin{tabular}{lllllll}
\hline PLA/PPCU & $100 / 0$ & $90 / 10$ & $80 / 20$ & $70 / 30$ & $60 / 40$ & $50 / 50$ \\
$W_{\mathrm{c}, \mathrm{x}}(\%)$ & 49.06 & 50.30 & 51.26 & 52.38 & 50.01 & 49.32
\end{tabular}

Here $q_{\text {max }}$ represents the position of the intensity maximum in a SAXS pattern, $X_{\mathrm{c}, 2}$ represents the crystallinity of the samples of SAXS, which was derived from DSC measurement. The obtained $q_{\mathrm{max}}, d_{\mathrm{ac}}, d_{\mathrm{c}}$ and $d_{\mathrm{a}}$ values are summarized in Table 6 . In Fig. 9, pure PLA exhibits a broader scattering peak, which can be observed around $q=0.128 \mathrm{~nm}^{-1}$. The scattering peaks gradually shifted in position to higher $q$ values with increasing PPCU content, which indicated the $d_{\mathrm{ac}}$ values decreased. In Table 6, the $d_{\mathrm{ac}}, d_{\mathrm{c}}$ and $d_{\mathrm{a}}$ values were $49.06,19.91$, and $29.14 \mathrm{~nm}$, respectively, for pure PLA. For the 50/50 PLA/PPCU blend, they became $28.8,11.69$, and $17.11 \mathrm{~nm}$, respectively. It is obvious that all of the values of $d_{\mathrm{ac}}, d_{\mathrm{a}}$ and $d_{\mathrm{c}}$ values decreased with increasing PPCU content. However, the decreases in both $d_{\mathrm{a}}$ and $d_{\mathrm{c}}$ were large. For example, the decrease in $d_{\mathrm{a}}$ was around $11.96 \mathrm{~nm}$ after blending $50 \mathrm{wt} \%$ PPCU as compared to that of neat PLA. Such significant decrease in both $d_{\mathrm{a}}$ and $d_{\mathrm{c}}$ suggested that PPCU could affect the crystalline of PLA. The size of spherulites became smaller with increasing PPCU.

This study used POM to determine the spherulite morphologies and growth rates of the pure PLA and PLA/PPCU blends that isothermally crystallized at predetermined temperatures $120{ }^{\circ} \mathrm{C}$ for $1 \mathrm{~h}$. Fig. 10 shows the polarized optical photomicrographs of several selected samples taken during the isothermal crystallization at $120{ }^{\circ} \mathrm{C}$ for $15 \mathrm{~min}$. From Fig. 10(a-d), the presence of PPCU in PLA/PPCU blends resulted in the nucleating density of the spherulites being increased, the size of the spherulites decreased and obscurer spherulites boundaries. From Fig. 10(e) and (f), the nucleating density of the spherulites were slightly lower. PPCU could form continuous phase due to the content up to $40 \mathrm{wt} \%$. Molten PPCU had the effects of solvent and plasticizer, and make it easier for PLA molecular chain motion so that the size of spherulites are more likely to grow up at $120{ }^{\circ} \mathrm{C}$.

However, it indicated that the content of PPCU in the blends affected the morphology of spherulites. PPCU had improved the crystallization degree for PLA. The crystallinity values in Tables 2 and 5 exhibit the order $W_{\mathrm{c}, \mathrm{x}}>X_{\mathrm{c}}$. The crystallinity determined from $X$-ray diffraction $\left(W_{\mathrm{c}, \mathrm{x}}\right)$ was equal to the sum of crystalline and interphase contents, while the measurement of fusion enthalpy by calorimetry $\left(X_{\mathrm{c}}\right)$ yields values which are equal to the

Table 6 SAXS values of pure PLA and PLA/PPCU blends

\begin{tabular}{llllll}
\hline PLA/PPCU $(\mathrm{wt} / \mathrm{wt})$ & $q_{\max }\left(\mathrm{nm}^{-1}\right)$ & $X_{\mathrm{c}}(\%)$ & $d_{\mathrm{ac}}(\mathrm{nm})$ & $d_{\mathrm{c}}(\mathrm{nm})$ & $d_{\mathrm{a}}(\mathrm{nm})$ \\
\hline $100 / 0$ & 0.128 & 40.6 & 49.06 & 19.91 & 29.14 \\
$90 / 10$ & 0.183 & 41.2 & 34.31 & 14.13 & 20.17 \\
$80 / 20$ & 0.194 & 41.9 & 32.37 & 13.56 & 18.80 \\
$70 / 30$ & 0.205 & 44.2 & 30.63 & 13.54 & 17.09 \\
$60 / 40$ & 0.216 & 43.9 & 29.07 & 12.76 & 16.31 \\
$50 / 50$ & 0.218 & 40.6 & 28.80 & 11.69 & 17.11
\end{tabular}

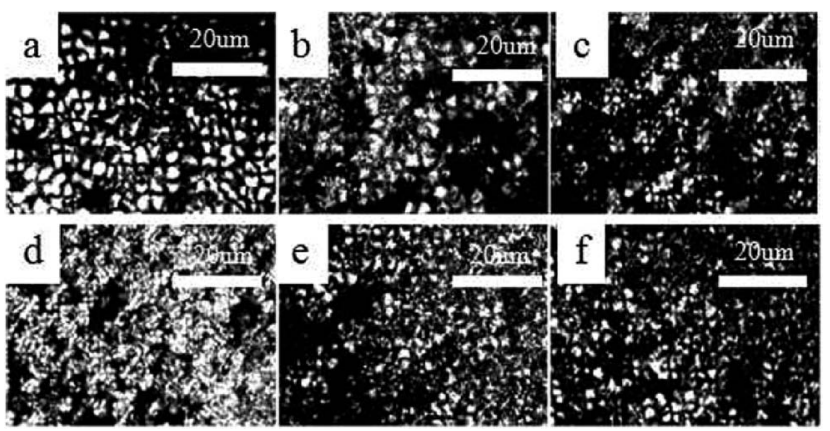

Fig. 10 Spherulitic growth process of pure PLA and PLA/PPCU blends at a crystallization temperature of $120{ }^{\circ} \mathrm{C}$ at $15 \mathrm{~min}$. (a) Pure PLA, (b) 90/10, (c) 80/20, (d) 70/30, (e) 60/40, (f) 50/50.

crystalline content. Imperfections of crystals are not easily distinguished from the amorphous phase. Therefore, some disagreements among the quantitative results of crystallinity by different measurement methods are frequently encountered. These results were in consistent with the crystallinity data from DSC (Table 2), WAXD, and SAXS measurement.

\section{Dynamic mechanical analysis}

Dynamic mechanical analysis was used to analyze the modulus changes of the blends. The storage modulus $\left(E^{\prime}\right)$-temperature curves of pure PLA and PLA/PPCU blends are exhibited in Fig. 11(a). It can be seen that PLA/PPCU blends show lower storage modulus than pure PLA from -25 to $80{ }^{\circ} \mathrm{C}$, indicating an increase in the flexibility of PLA imparted by the PPCU. Above $50{ }^{\circ} \mathrm{C}, E^{\prime}$ decreases rapidly because of the glass transition of PLA and reaches a minimal value around $65{ }^{\circ} \mathrm{C}$.

This reflects an enhancement of sample rigidity resulting from the cold crystallization process detected using DSC. The $\tan \delta$-temperature curves of pure PLA and PLA/PPCU blends are exhibited in Fig. 11(b). The Loss factor $\tan \delta=E^{\prime \prime} / E^{\prime}$, it can be seen in Fig. 11(b) that $\tan \delta$ decrease constantly with increasing PPCU content. This indicates the elastic property of blends was improved with the addition of PPCU, and toughness was increased significantly. Fig. 11(b) showed obvious tendencies that the glass transition of PLA/PPCU blends moved toward the temperature of the glass transition of PPCU. It can be seen that the glass transition peak of PLA has evidently shifted to low temperature, and indicates that the blends are tended to toughness.

\section{Enzymatic hydrolysis}

The biodegradability of PLA/PPCU blends is extremely important for the potential application of the materials in the future. Proteinase $\mathrm{K}$ is the only protein that can directly produce enzymatic hydrolysis without hydrolysis. Therefore, the analysis of weight loss data evaluated the degradation of PLA/PPCU blends. As shown in Fig. 12(a), the weight loss of the blends increased with time for all samples. The weight loss of the PLA/ PPCU blends was decreased from 65.9 to $50.3 \mathrm{wt} \%$ by incorporation of the PPCU. The rate of enzymatic degradation could be 


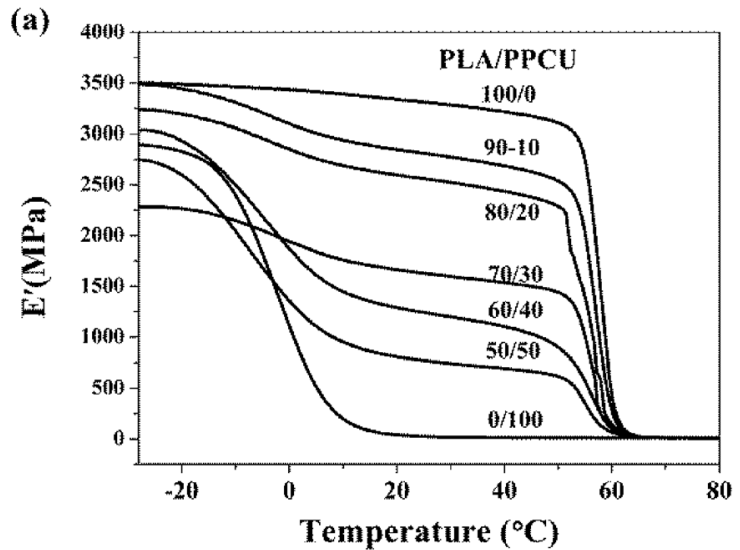

(b)

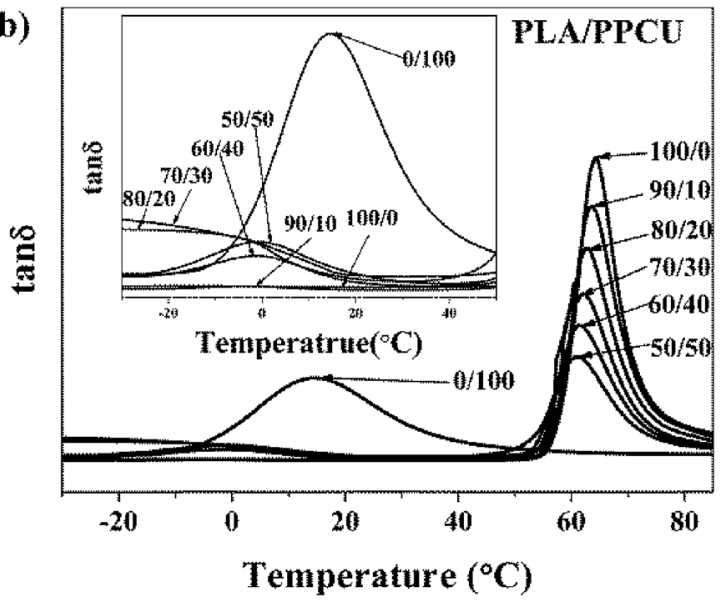

Fig. 11 (a) Dynamic storage modulus, (b) tan $\delta$ of pure PLA and PLA/ PPCU blends as a function of temperature.

determined from the slope of the weight loss against time. There was little difference among the five samples for the enzymatic degradation before six days due to the incubation period for proteinase $\mathrm{K}$.

The weight loss $\left(W_{\mathrm{L}}\right)$ of the samples was calculated via eqn (13):

$$
W_{\mathrm{L}}(\%)=\frac{\left(m_{0}-m_{i}\right)}{m_{0}} \times 100
$$

where $m_{0}$ is the weight of the samples before degradation and $m_{\mathrm{i}}$ is the dry weight of the degraded samples.

After six days, the blends began to degradation at a faster rate. It indicated that the addition of PPCU had no obvious influence on the enzymatic degradation rate of PLA/PPCU.

The relative weight loss of PLA ( $\left.W_{\mathrm{L}, \mathrm{PLA}}\right)$ of the samples was calculated via eqn (14):

$$
W_{\mathrm{L}, \mathrm{PLA}}=\frac{W_{\mathrm{L}}}{W_{\mathrm{PLA}}}
$$

where $W_{\text {PLA }}$ is the content of PLA in the samples and $W_{\mathrm{L}}$ is the weight loss of the PLA/PPCU samples.

From Fig. 12(b), it can be seen that the enzymatic degradation rate of PLA was obvious improved with gradually increasing PPCU content. The relative weight loss of PLA was improved
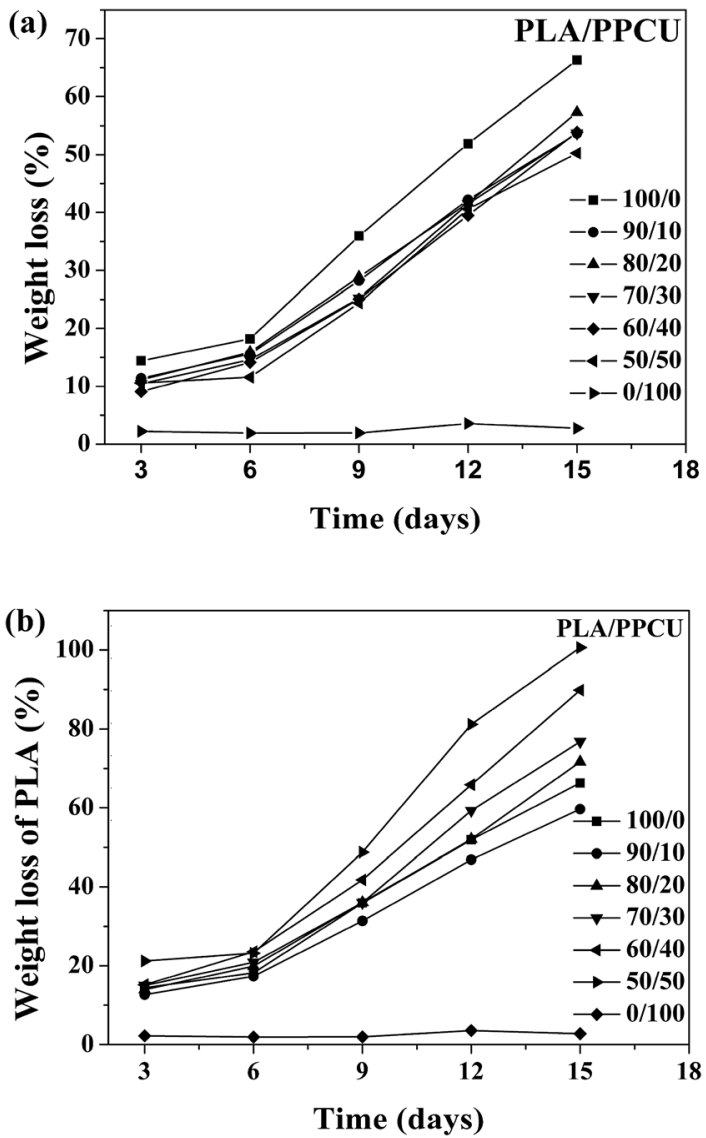

Fig. 12 (a) The weight loss of PLA/PPCU blends and (b) the weight loss of PLA, as a function of time during the enzymatic degradation.

from 59.6 to $100 \%$. The PLA was entirely degraded in the PLA/ PPCU 50/50 blends at 15th days. It can be comprehended that the PLA was hydrolyzed before degraded by enzyme, and the hydrolysis ability of PLA was improved because of PLA being dispersed by PPCU. There are more active points after PLA being hydrolyzed, then exhibit that PPCU have promoted the enzymatic degradation rate of PLA.

\section{Conclusions}

The PLA/PPCU blends were prepared via twin screw extruder. The mechanical test results showed that PLA could be remarkably toughened by in addition of PPCU. The impact strength of PLA was enhanced from 4.8 to $102.8 \mathrm{~kJ} \mathrm{~m}^{-2}$ for the 50/50 PLA/ PPCU blend. The toughening-mechanism investigation revealed that shear yielding occurred in the PLA matrix as induced by the cavitation of PPCU particles. DSC analysis revealed that PPCU had distinct effect on the melting process, the temperature of cold crystallization had been obviously improved with the increase of PPCU content for PLA. PPCU enhanced the crystallization degree of PLA, but the function of promoting was weaken when the content of PPCU further increased. But the crystallization rate of PLA/PPCU blends was decreased with increasing PPCU, and the blends show up toughness. The crystallization density and spherulites size of 
PLA were obviously affected with the addition of PPCU, but not alter the crystalline type of PLA. The microstructure of the blends changed with the addition of PPCU. And the result indicated that the microstructure of blend was obviously changed when the PPCU content was $20 \mathrm{wt} \%$. The results were further demonstrated in isothermal crystallization kinetics of blend. When the blend without PPCU content had a stress relaxation mechanism that depended on the PLA matrix, and the blends with PPCU content from 10 to $50 \mathrm{wt} \%$ had similar stress relaxation mechanism that depended on the PPCU constituents. The enzymatic degradation rate of PLA was obvious improved with gradually increasing PPCU content. Moreover, the study in this work provided a method for toughening modification of PLA and expanding its application.

\section{Conflicts of interest}

This manuscript are no conflicts to other articles.

\section{Acknowledgements}

This work was supported by the fund of Science \& Technology Bureau of Jilin Province of China (No. 20160307001GX), Science \& Technology Bureau of Changchun City of China (No. 16SS03), Science \& Technology Bureau of Jilin City of China (No. 20163206), and Chinese Science Academy (Changchun Branch) (No. 2017SYHZ0016).

\section{Notes and references}

1 J. H. Qiu, Y. W. Zhang, X. HMeng, H. Q. Zhang and J. D. Liu, Polym. Int., 2010, 59, 78-84.

2 W. C. Lai and J. P. Liao, Mater. Chem. Phys., 2013, 139, 161168.

3 K. S. Anderson and M. A. Hillmyer, Polymer, 2004, 45, 88098823.

4 N. Bitinis, R. Verdejo, P. Cassagnau and M. A. LopezManchado, Mater. Chem. Phys., 2011, 129, 823-831.

5 N. Bitinis, R. Verdejo, E. M. Maya, E. Espuche, P. Cassagnau and M. A. Lopez-Manchado, Compos. Sci. Technol., 2012, 72, 305-313.

6 M. Jonoobi, J. Harun, A. P. Mathew and K. Oksman, Compos. Sci. Technol., 2010, 70, 1742-1747.

7 Y. J. Chen, L. J. Han, Z. L. Li, J. J. Kong, D. D. Wu, Z. W. Cao and L. S. Dong, RSC Adv., 2017, 7, 712-719.

8 Y. P. Hao, H. Y. Liang, J. J. Bian, S. S. Sun, H. L. Zhang and L. S. Dong, Polym. Int., 2014, 63, 660-666.

9 M. S. Z. M. Desa, A. Hassan, A. Arsad, R. Arjmandi and N. N. B. Mohammad, J. Appl. Polym. Sci., 2016, 133, 44344.

10 N. A. Rosli, I. Ahmad, F. H. Anuar and I. Abdullah, Polym. Test., 2016, 54, 196-202.

11 N. J. Wu, H. Zhang and G. L. Fu, ACS Sustainable Chem. Eng., 2017, 5, 78-84.

12 L. Mascia, R. Su, J. Clarke, Y. Lou and E. Mele, Eur. Polym. J., 2017, 87, 241-254.

13 A. Masek, K. Diakowska and M. Zaborski, J. Therm. Anal. Calorim., 2016, 125, 1467-1476.
14 P. Sukpuang, M. Opaprakasit, A. Petchsuk, P. Tangboriboonrat, P. Sojikul and P. Opaprakasit, J. Elastomers Plast., 2016, 48, 105-121.

15 J. J. Li, J. Li, D. Feng, J. F. Zhao, J. R. Sun and D. G. Li, RSC Adv., 2017, 7, 28889-28897.

16 Z. Cao, Y. Lu, C. Zhang, Q. Zhang, A. Zhou, Y. C. Hu, D. Wu, G. L. Tao, F. H. Gong, W. Z Ma and C. L. Liu, J. Appl. Polym. Sci., 2017, 134, 44895.

17 T. M. Dias Fernandes, M. C. Amorim Moreira Leite, A. M. Furtado de Sousa, C. R. Guimaraes Furtado, V. A. Escocio and A. L. Nazareth da Silva, Polym. Bull., 2017, 74, 1713-1726.

18 H. W. Pan, D. D. Ju, Y. Zhao, Z. Wang, H. L. Yang, H. L. Zhang and L. S. Dong, Fibers Polym., 2016, 17, 15401549.

19 J. B. Zeng, Y. D. Li, Q. Y. Zhu, K. K. Yang, X. L. Wang and Y. Z. Wang, Polymer, 2009, 50, 1178-1186.

20 V. Jaso, M. Cvetinov, S. Rakic and Z. S. Petrovic, J. Appl. Polym. Sci., 2014, 131, 41104.

21 L. D. Feng, X. C. Bian, Y. Cui, Z. M. Chen, G. Li and X. S. Chen, Macromol. Chem. Phys., 2013, 214, 824-834.

22 E. Oliaei, B. Kaffashi and S. Davoodi, J. Appl. Polym. Sci., 2016, 133, 43104.

23 L. Y. Zhou, G. Y. Zhao and W. Jiang, Ind. Eng. Chem. Res., 2016, 55, 5565-5573.

24 W. Zou, R. Y. Chen, G. Z. Zhang, H. C. Zhang and J. P. Qu, Polym. Adv. Technol., 2016, 27, 1430-1437.

25 K. Pongtanayut, C. Thongpin and O. Santawitee, Energy Procedia, 2013, 34, 888-897.

26 T. Kanzawa and K. Tokumitsu, J. Appl. Polym. Sci., 2011, 121, 2908-2918.

27 H. Y. Liang, Y. P. Hao, J. J. Bian, H. L. Zhan, L. S. Dong and H. X. Zhang, Polym. Eng. Sci., 2015, 55, 386-396.

28 H. L. Zhang, H. Y. Liang, J. J. Bian, Y. P. Hao, L. J. Han, X. M. Wang, G. B. Zhang, S. R. Liu and L. S. Dong, Polym. Int., 2014, 63, 1076-1084.

29 L. Wang, W. M. Gramlich and D. J. Gardner, Polymer, 2017, 114, 242-248.

30 H. L. Zhang, N. A. Liu, X. H. Ran, C. Y. Han, L. J. Han, Y. G. Zhuang and L. S. Dong, J. Appl. Polym. Sci., 2012, 125, E550-E561.

31 W. Li, Y. Zhang, D. D. Wu, Z. L. Li, H. L. Zhang, L. S. Dong, S. L. Sun, Y. J. Deng and H. X. Zhang, Adv. Polym. Technol., 2015, DOI: 10.1002/adv.21632.

32 S. L. Sun, M. Y. Zhang, H. X. Zhang and X. M. Zhang, J. Appl. Polym. Sci., 2011, 122, 2992-2999.

33 X. F. Ma, J. G. Yu and N. Wang, J. Polym. Sci., Part B: Polym. Phys., 2006, 44, 94-101.

34 Y. Y. Chen, Z. X. Liu, S. Han, J. Han and D. Y. Jiang, J. Appl. Polym. Sci., 2016, 133, 43667.

35 S. J. Wang, Y. H. Huang, B. Liao, G. Lin, G. M. Cong and L. B. Chen, Int. J. Polym. Anal. Charact., 1997, 3, 131-143.

36 C. B. Bucknall and D. R. Paul, Polymer, 2013, 54, 320-329.

37 E. W. Fischer, H. J. Sterzel and G. Wegner, Colloid Polym. Sci., 1973, 251, 980-990.

38 M. Avrami, J. Chem. Phys., 1939, 7, 1103-1112.

39 M. Avrami, J. Chem. Phys., 1940, 8, 212-224. 
40 B. Wunderlich, Macromolecular Physics, Academic, New York, 1976, vol. 2.

$41 \mathrm{~J}$. Yu and J. He, Polymer, 2000, 41, 891-898.

42 H. Marubayashi, S. Asai and M. Sumita, Macromolecules, 2012, 45, 1384-1397.
43 J. H. Wu, X. X. Zou, B. Jing and W. L. Dai, Polym. Eng. Sci., 2015, 55, 1104-1112.

44 Y. Zhao, Y. Zhang, Z. L. Li, H. W. Pan, Q. L. Dong, L. J. Han, H. L. Zhang and L. S. Dong, Korean J. Chem. Eng., 2016, 33, 1104-1114. 